\title{
Effectiveness of preoperative planning in the restoration of balance and view in ankylosing spondylitis
}

\author{
Roy R. Pigge, B.Sc.(Med), ${ }^{1}$ Famke J. Scheerder, M.D., ${ }^{1}$ Theo H. Smit, Ph.D., ${ }^{2}$ \\ Margriet G. Mullender, Ph.D., ${ }^{1}$ And Barend J. van Royen, M.D., Ph.D. ${ }^{1}$ \\ Departments of ${ }^{1}$ Orthopaedic Surgery and ${ }^{2}$ Physics and Medical Technology, VU University Medical \\ Centre, Amsterdam, The Netherlands
}

\begin{abstract}
Object. The object of this study was to assess the effectiveness of preoperative planning in the restoration of balance and view angle in patients treated with lumbar osteotomy in ankylosing spondylitis (AS).

Methods. The authors prospectively analyzed 8 patients with a thoracolumbar kyphotic deformity due to AS that was treated using a closing wedge osteotomy (CWO) of the lumbar spine to correct sagittal imbalance and horizontal view. Preoperative planning to predict postoperative balance, defined by the sagittal vertical axis (SVA) and the sacral endplate angle (SEA), and the view angle, defined by the chin-brow to vertical angle (CBVA), was performed using the ASKyphoplan computational program.

Results. All patients were treated with a CWO at level L-4 and improved in balance and view angle. The mean correction angle was $35^{\circ}$ (range $24-47^{\circ}$ ). The postoperative SEA improved from 21 to $36^{\circ}$ for a mean correction of $15^{\circ}$. In addition, the SVA and CBVA improved significantly. Note, however, that the postoperative results did not exactly reflect the predicted values of the analyzed parameters.

Conclusions. Preoperative planning for the restoration of balance and view angle in AS improves understanding of the biomechanical and clinical effects of a correction osteotomy of the lumbar spine. The adaptation of basic clinical and biomechanical principles to restore balance is advised in such a way that the individual SEA is corrected by $15^{\circ}$ (maximum $40^{\circ}$ ) in relation to the horizon and C-7 is balanced exactly above the posterosuperior corner of the sacrum. (DOI: 10.3171/FOC/2008/24/1/E7)
\end{abstract}

\section{KEY WORDS • ankylosing spondylitis • lumbar spine • osteotomy $\bullet \quad$ surgical planning}

$\mathrm{D}$ ESPITE adequate conservative treatment, AS can lead to severe fixed TLKD of the spine. Such fixed spinal kyphosis can cause severe impairment in the quality of life. Patients with this pathophysiology describe a constant feeling of leaning forward, which frequently results in pain and fatigue in the spine as well as the thighs and buttocks, given that the muscles are under constant strain from trying to maintain an erect posture. In addition, pulmonary function decreases because the rigidity of the thoracic cage prevents chest expansion and because diaphragmatic respiration declines due to compression of the abdominal viscera by the inferior margin of the rib cage. The chief symptom, however, is an inability to look straight ahead to the horizon, which restricts many of the patient's daily activities, for example, interpersonal com-

Abbreviations used in this paper: $\mathrm{AS}=$ ankylosing spondylitis; $\mathrm{CBVA}=$ chin-brow to vertical angle; $\mathrm{CWO}=$ closing-wedge osteotomy; PSCS = posterosuperior corner of the sacrum; SEA = sacral endplate angle; SVA = sagittal vertical axis; SVA(SEA 40) $=$ SVA with the SEA corrected $40^{\circ}$ to the horizon; TLKD $=$ thoracolumbar kyphotic deformity. munication, walking on the street, or driving a car. Occasionally, psychosocial aspects play a role too; patients tend to feel socially unaccepted and are troubled by their appearance.

Corrective osteotomy of the spine can be considered in these patients. The goal of such a surgical procedure is to restore the patient's capacity to see the horizon, view angle, and sagittal balance of the ankylosed spine so that the legs remain straight during normal standing and so that little muscular effort is needed to balance the spine. Generally, a CWO of the lumbar spine is performed to correct the TLKD in patients with AS. This procedure has been used in clinical practice for $\geq 60$ years, and its value in correcting the spinal deformity in AS has been well established. $1,3,8,10$

The effect of a spinal osteotomy on balance and the view angle depends on both the correction angle and the level at which the osteotomy is performed. Adequate planning is advised to predict the effect of a lumbar osteotomy on sagittal balance and the view angle. In an effort to predict the clinical outcome of a lumbar osteotomy, several methods of preoperative planning have been described. ${ }^{4,5,6,11,14}$ Recently, we developed a biomechanical and mathematical 
procedure for planning sagittal plane corrective osteotomies in AS. Subsequently, we introduced the ASKyphoplan computational program, which was based on these biomechanical and mathematical principles and was easily applied in daily practice. ${ }^{12}$ The ASKyphoplan computer program is free for use at www.stega.nl (subheading "Research").

The clinical utility and effectiveness of preoperative planning in patients treated with spinal osteotomy for an AS-related TLKD has never been reported, and thus we undertook a prospective cohort study to analyze the efficacy of preoperative planning in the restoration of sagittal balance and view angle following a lumbar CWO.

\section{Parameters for Balance and the View Angle}

The sagittal balance of a patient with a TLKD caused by AS is defined by the position of the spine in relation to the neutral position of the pelvis. The position of the pelvis in the gravitational field is expressed in terms of pelvic tilt, sacral slope, or SEA. In healthy individuals, the SEA is on the order of $40^{\circ} .{ }^{2,11}$ In patients with an AS-induced severe TLKD, however, this angle is acutely decreased as a result of a compensation maneuver in the lower extremities. The pelvic tilt or SEA in such patients is reduced by extension of the hips and flexion of the knees and ankles, and thus is a direct indication of an unbalanced spine. Therefore, in planning an osteotomy, it is most practical to start from a well-balanced position of the pelvis, that is, with an SEA of $40^{\circ}$. The position of the spine in patients with AS is expressed by the SVA, which is defined as the distance between the plumb line from the C-7 vertebral body and the PSCS (in $\mathrm{mm}$ ). To express uncompensated balance of the spine, the SVA is measured after correcting the SEA to $40^{\circ}$ in relation to the horizon, that is, SVA(SEA 40). To prevent overcorrection, we hypothesized that the optimal postoperative SVA in a patient with AS lies between 50 and $100 \mathrm{~mm}$ anterior to $\mathrm{S}-1 .{ }^{11}$

The view angle is defined by the CBVA, which is the angle between the vertical reference line and a line parallel to the chin and brow of the patient while he or she stands in a relaxed position with hips and knees extended. In patients with a severe TLKD caused by AS, the CBVA is increased. Functional restoration of the CBVA to as close to normal as possible is of the utmost importance. Given that a spinal osteotomy alters both the CBVA and sagittal balance, overcorrection of the CBVA following a spinal osteotomy should be prevented. ${ }^{7}$ Overcorrection in patients with a TLKD caused by AS has been defined as a CBVA $<-10^{\circ}$.

\section{Clinical Material and Methods}

We prospectively analyzed a cohort of eight patients (7 men and 1 woman) with a severe TLKD due to AS and undergoing a CWO of the lumbar spine for correction of sagittal imbalance and horizontal view. The mean age at the time of the operation was 40 years (range 28-51 years). The indications for surgery were a severe ankylosed TLKD, an inability to look straight ahead, and progressive thoracolumbar pain and fatigue. All patients had problems with daily activities and social life. None of the patients had secondary arthritis or subsequent flexion contractures of the hip joints. Patients who had undergone revision operations were excluded from this study. The entire surgical procedure, including patient positioning, anesthesia, and surgery, was performed according to a technique described previously. ${ }^{13}$

Preoperative surgical planning was performed with the ASKyphoplan computational program in all patients. ${ }^{12}$ The principles, a description, and the practical implications of the program have been reported recently. By using this program, we can calculate the preferred level of osteotomy and the amount of correction that can be achieved with a CWO in relation to the SVA and CBVA correction. The radiograph was rotated until the hypothetically ideal SEA was $40^{\circ}$ to the horizon (SVA[SEA 40]).

Preoperative clinical photographs were obtained to evaluate the CBVA. A standard full-length radiograph of the whole spine was obtained while the patient remained standing in a relaxed position. The center of the body of C-7, the PSCS, and the SEA were marked on the radiograph. In addition, the 50-mm grid of the film was measured and marked for calibration. The marked radiograph was saved in a JPEG format for each patient, making it possible to upload the radiograph into the ASKyphoplan program.

A postoperative full-length radiograph of the whole spine and radiographs of the lumbar spine were obtained to measure the correction angle achieved and to reevaluate each patient's balance as expressed by the SEA and SVA (SEA 40). The correction angle was measured in degrees by calculating the Cobb angle between the upper and lower endplate of the surgically treated vertebral body. Postoperative clinical photographs were obtained to measure and evaluate each patient's CBVA.

\section{Results}

\section{Preoperative Data}

The preoperative data for all the patients are shown in Table 1. Preoperatively, the mean SEA was $21^{\circ}$ (range 14-36 ${ }^{\circ}$, the mean compensated SVA was $164 \mathrm{~mm}$ (range 67-273 $\mathrm{mm}$ ), the mean uncompensated SVA(SEA 40) was $300 \mathrm{~mm}$ (range 161-387 $\mathrm{mm}$ ), and the mean CBVA was $35^{\circ}$ (range $\left.11-64^{\circ}\right)$.

\section{Preoperative Planning}

A posterior-based CWO at level L-4 was planned in all patients. The ideal SEA was defined at $40^{\circ}$. In the first 3

TABLE 1

Summary of preoperative values in 8 patients with an AS-induced TLKD

\begin{tabular}{ccccc}
\hline \hline $\begin{array}{c}\text { Case } \\
\text { No. }\end{array}$ & SEA $\left(^{\circ}\right)$ & SVA $(\mathrm{mm})$ & $\begin{array}{c}\text { SVA(SEA } \\
\text { 40) in mm }\end{array}$ & CBVA $\left(^{\circ}\right)$ \\
\hline 1 & 26 & 136 & 254 & 11 \\
2 & 17 & 156 & 325 & 64 \\
3 & 36 & 130 & 161 & 22 \\
4 & 14 & 67 & 267 & 30 \\
5 & 21 & 244 & 356 & 47 \\
6 & 24 & 273 & 364 & 27 \\
7 & 14 & 190 & 387 & 63 \\
8 & 15 & 116 & 287 & 15 \\
\hline
\end{tabular}


TABLE 2

Summary of preoperative planning data in 8 patients with $A S^{*}$

\begin{tabular}{cccc}
\hline \hline $\begin{array}{c}\text { Case } \\
\text { No. }\end{array}$ & $\begin{array}{c}\text { Predicted SVA } \\
(\text { SEA 40) in mm }\end{array}$ & $\begin{array}{c}\text { Correction } \\
\text { Angle }\left(^{\circ}\right)\end{array}$ & $\begin{array}{c}\text { Predicted CBVA } \\
\text { Correction }\left(^{\circ}\right)\end{array}$ \\
\hline 1 & 24 & 30 & 3 \\
2 & 89 & 35 & 9 \\
3 & 28 & 20 & 14 \\
4 & 75 & 29 & 9 \\
5 & 75 & 49 & 29 \\
6 & 75 & 50 & 33 \\
7 & 75 & 43 & 17 \\
8 & 75 & 36 & 10 \\
\hline
\end{tabular}

* In all patients the level of the osteotomy was L-4 and the SEA was $40^{\circ}$.

patients surgical plans were made according to the operation angle that would lead to an optimal correction of the CBVA and SVA. Calculations were based on a desirable correction that would not induce overcorrection of the view angle (CBVA; Table 2). Plans were made in the last 5 patients according to a predicted postoperative SVA of 75 $\mathrm{mm}$. Calculations in these cases were based on the hypothetically desirable postoperative SVA that would lead to an achievable correction angle but not overcorrection of the CBVA (Fig. 1). ${ }^{11}$
TABLE 3

Postoperative results in 8 patients who underwent spinal osteotomy for TLKD

\begin{tabular}{cccrcc}
\hline \hline $\begin{array}{c}\text { Case } \\
\text { No. }\end{array}$ & $\begin{array}{c}\text { Correc- } \\
\text { tion }\left(^{\circ}\right)\end{array}$ & SEA $\left(^{\circ}\right)$ & $\begin{array}{r}\text { SVA } \\
(\mathrm{mm})\end{array}$ & $\begin{array}{c}\text { SVA(SEA } \\
\text { 40) in mm }\end{array}$ & CBVA $\left(^{\circ}\right)$ \\
\hline 1 & 33 & 44 & 54 & 21 & 3 \\
2 & 27 & 32 & 7 & 73 & -6 \\
3 & 24 & 55 & 29 & -96 & 12 \\
4 & 36 & 32 & -25 & 40 & 19 \\
5 & 47 & 34 & 58 & 104 & 26 \\
6 & 43 & 42 & 119 & 106 & 6 \\
7 & 40 & 24 & 0 & 152 & 27 \\
8 & 34 & 22 & 10 & 146 & -3 \\
\hline
\end{tabular}

\section{Postoperative Results}

The results following surgery are shown in Table 3 . There were no complications during surgery or follow-up treatment. In all patients we were able to achieve a correction within a range of $-8-7^{\circ}$ of the planned correction angle. The mean correction angle was $35^{\circ}$ (range $24-47^{\circ}$ ).

In all patients, balance and the view angle improved clinically. The mean postoperative SEA improved from 21 to $36^{\circ}$ (range $22-55^{\circ}$ ) with a mean correction of $15^{\circ}$. Postoperative balance, expressed by SVA(SEA 40), improved

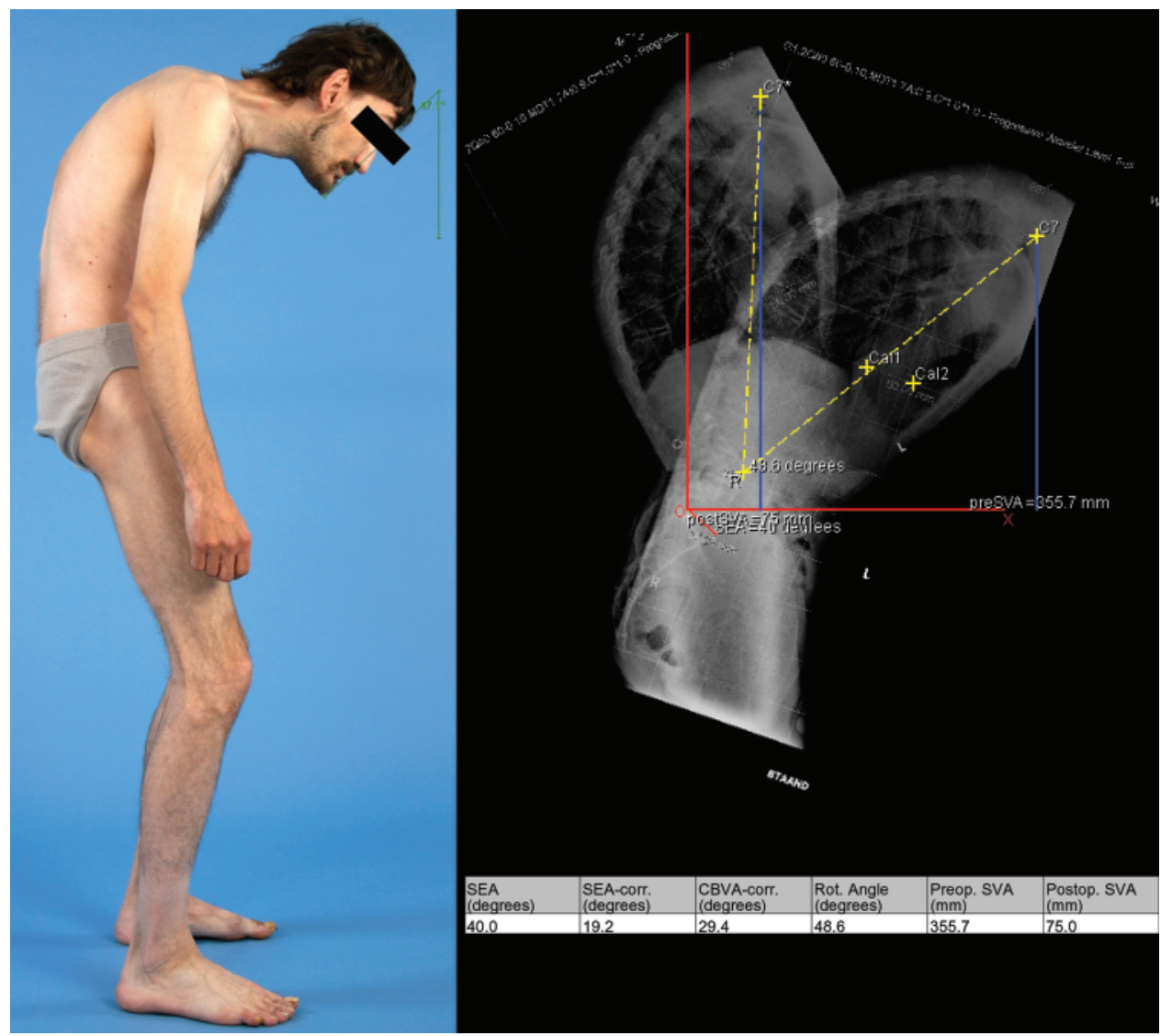

FIG. 1. Case 5. A: Preoperative photograph depicting the patient's clinical appearance. B: Preoperative ASKyphoplan report showing preoperative parameters: CBVA of $47^{\circ}$, SEA of $21^{\circ}$, and SVA of $244 \mathrm{~mm}$. Rotation of the radiograph onto the coordinate system with the SEA at $40^{\circ}$ results in an SVA(SEA 40) of $356 \mathrm{~mm}$. A $49^{\circ}$ osteotomy at L-4 predicts the postoperative SVA(SEA 40) of $75 \mathrm{~mm}$. The predicted CBVA correction is $29^{\circ}$. 


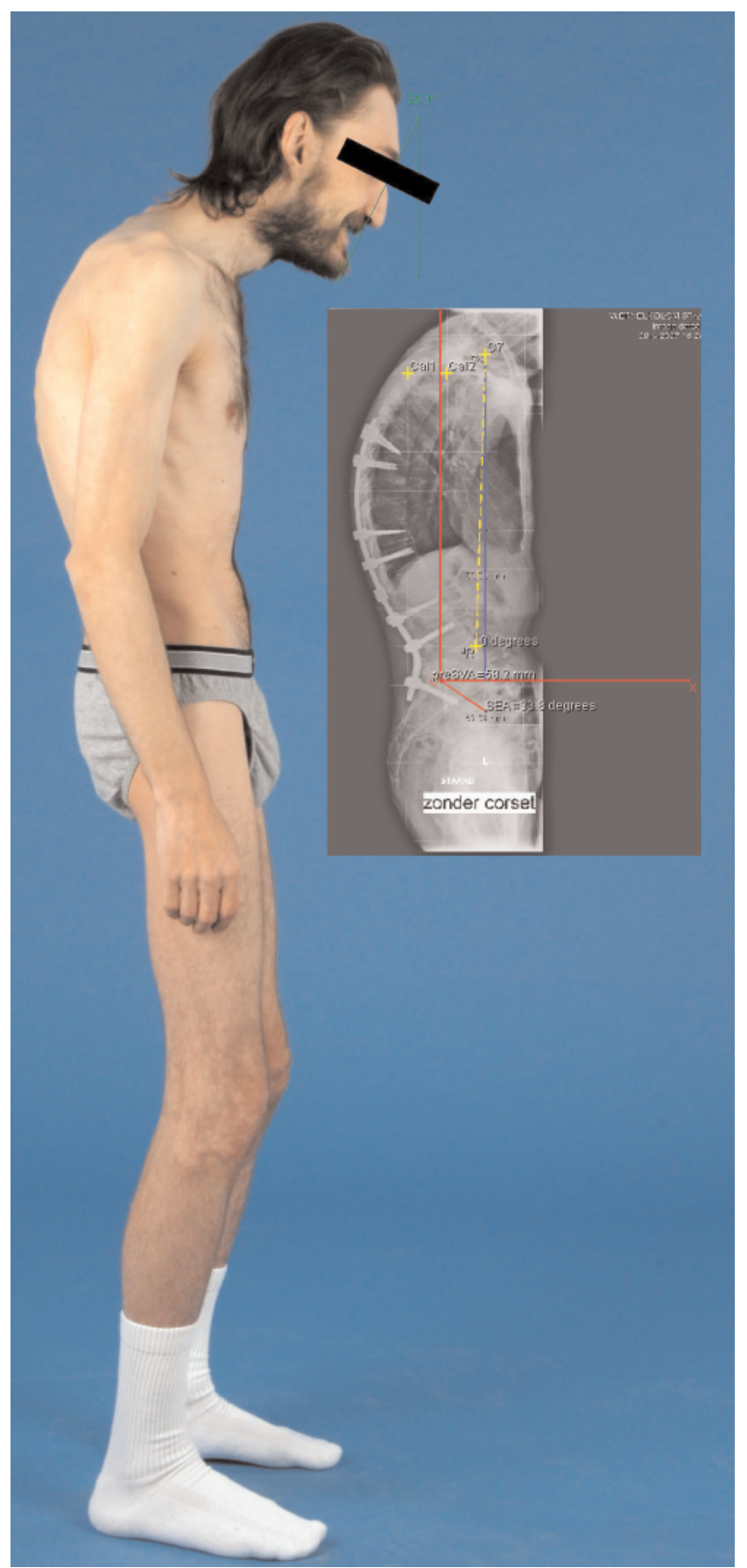

FIG. 2. Case 5. Photograph illustrating the patient's clinical appearance following the CWO. Inset: Final ASKyphoplan report showing postoperative parameters. Postoperative radiograph of the lumbar spine showed a correction of $47^{\circ}$ in L-4. Postoperative full-length lateral radiograph of the whole spine showed an SEA of $34^{\circ}$ and SVA of $58 \mathrm{~mm}$. The postoperative SVA(SEA 40) with the SEA rotated at $40^{\circ}$ was $104 \mathrm{~mm}$. The clinical postoperative CBVA was $26^{\circ}$.

by $232 \mathrm{~mm}$ from 300 to $68 \mathrm{~mm}$ (range $-96-152 \mathrm{~mm}$ ). However, the postoperative SVA(SEA 40) differed considerably from the predicted SVA(SEA 40) in all patients in whom plans had been made according to a predicted post- operative SVA of $75 \mathrm{~mm}$. Moreover, in 1 patient (Case 3) in whom plans had been made according to the operation angle that would lead to an optimal correction of the CBVA and SVA, the postoperative SVA(SEA 40) differed considerably from the predicted value.

The mean postoperative CBVA improved by $24^{\circ}$, from 35 to $11^{\circ}$ (range $-6-26^{\circ}$ ). Note, however, that the CBVA achieved postoperatively did not correlate with the planned CBVA correction (Fig. 2).

\section{Discussion}

Although adequate preoperative planning for sagittal plane corrective osteotomies of the spine in AS appears essential to reliably predicting the effect of surgical correction on the restoration of balance and view, the effectiveness of this step has not been reported. We prospectively analyzed data in a cohort of patients who had undergone planning and treatment for sagittal plane corrective osteotomies according to our recently described method of visualizing the relationship between the osteotomy angle and the level of osteotomy in connection to sagittal balance and CBVA. ${ }^{11,12}$

The postoperative results in this cohort showed that the use of the ASKyphoplan computational program for preoperative planning increases our understanding of the biomechanical and clinical effects of a lumbar spine correction osteotomy on the restoration of balance and view in patients with a rigid TLKD caused by AS. Balance and view angle improved in all patients. There was no overcorrection of the view angle, expressed by the CBVA, and the balance expressed by the SVA(SEA 40) improved in all cases.

Unfortunately, the postoperative results in this cohort did not exactly match the predicted values of the analyzed parameters. Can the different results be explained by the planning procedure itself? The explanation may be less obvious and is related to the difficulties encountered clinically and biomechanically. First, in the process of preoperative planning it is important to determine both how much correction is desirable and how much is achievable. The amount of correction that can be achieved in the sagittal plane by performing a posterior-based osteotomy is limited by the size of the closing wedge that can be safely created in the lumbar spine and then closed with modern pedicle fixation devices. Second, the ideal position of the pelvis in the gravitational field, expressed by the SEA as a parameter for balance in AS, may differ from that in healthy individuals. In healthy volunteers, the SEA makes an angle of $\sim 40^{\circ}$ with the horizon on a standing lateral radiographic projection. 2,11 However, should patients with an ASinduced rigid TLKD undergo correction to this assumed normal angle? We showed that the average postoperative

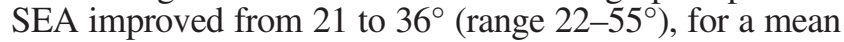
correction of $15^{\circ}$. An increase in the SEA as a parameter of the correction of balance has also been demonstrated in 2 recent papers. ${ }^{4,6}$ In the study by Min et al. ${ }^{4}$ the mean postoperative SEA was $31.8^{\circ}$ with a mean correction of $20^{\circ}$, and in the study by Ruf et al. ${ }^{6}$ the mean postoperative SEA was $40^{\circ}$ with a mean correction of $17^{\circ}$. Third, balance expressed by the SVA(SEA 40) is measured by calculating the horizontal distance between the plumb line from C-7 and the PSCS with the SEA rotated $40^{\circ}$ to the horizon. However, the optimum postoperative SVA(SEA 40) in 
patients with TLKD due to AS is not known. We hypothesized that the postoperative SVA(SEA 40) from C-7 should be between 50 and $100 \mathrm{~mm}$ anterior to the PSCS to prevent overcorrection of the ankylosed TLKD in AS. ${ }^{11}$ For that reason, a postoperative SVA of $75 \mathrm{~mm}$ was planned in our cases. Realize, however, that many parameters - height of the patient, thoracic and abdominal girth, posture, and position of the head and arms-influences balance in patients with AS.

Current data suggest that some principal clinical and biomechanical assumptions must be reconsidered in patients with a rigid TLKD caused by AS. Integration of the current data with the aforementioned biomechanical principles for planning in AS leads to the conclusion that a relative increase of $15^{\circ}$ in the SEA, up to a maximum of $40^{\circ}$, may be preferable in patients with a rigid TLKD caused by AS. In addition, balancing the spine by defining the SVA in C-7 exactly above the PSCS excludes differences in height, posture, thoracic and abdominal girth, and position of the head and arms. Given our small study group, the effect of this new hypothesis should be analyzed in further studies.

\section{Conclusions}

Preoperative planning increases understanding of the biomechanical and clinical effects of a lumbar spine correction osteotomy on the restoration of balance and view in patients with AS. By using preoperative clinical assumptions in the ASKyphoplan computer program, the predicted values of balance and view angle could not be achieved after surgery. Hence, the clinical and biomechanical principles in patients with a severe TLKD caused by AS cannot be extrapolated to normal sagittal spinal values. Therefore, we advise planning the level of osteotomy and the degrees of correction in such a way that the SEA is corrected by $15^{\circ}$ (maximum $40^{\circ}$ ) to the horizon and balancing C-7 exactly above the PSCS.

\section{References}

1. Chen IH, Chien JT, Yu TC: Transpedicular wedge osteotomy for correction of thoracolumbar kyphosis in ankylosing spondylitis: experience with 78 patients. Spine 26: E354-E360, 2001

2. Jackson RP, Peterson MD, McManus AC, Hales C: Compensatory spinopelvic balance over the hip axis and better reliability in measuring lordosis to the pelvic radius on standing later- al radiographs of adult volunteers and patients. Spine 23: 1750-1767, 1998

3. La Chapelle EH: Osteotomy of the lumbar spine for correction of kyphosis in a case of ankylosing spondylarthritis. J Bone Joint Surg Am 28:851-858, 1946

4. Min K, Hahn F, Leonardi M: Lumbar spinal osteotomy for kyphosis in ankylosing spondylitis: the significance of the whole body kyphosis angle. J Spinal Disord Tech 20:149-153, 2007

5. Ondra SL, Marzouk S, Koski T, Silva F, Salehi S: Mathematical calculation of pedicle subtraction osteotomy size to allow precision correction of fixed sagittal deformity. Spine 31:E973-E979, 2006

6. Ruf M, Wagner R, Merk H, Harms J: [Preoperative planning and computer assisted surgery in ankylosing spondylitis.] Z Orthop Ihre Grenzgeb 144:52-57, 2006 (Ger)

7. Sengupta DK, Khazim R, Grevitt MP, Webb JK: Flexion osteotomy of the cervical spine: a new technique for correction of iatrogenic extension deformity in ankylosing spondylitis. Spine 26:1068-1072, 2001

8. Smith-Petersen MN, Larson CB, Aufranc OE: Osteotomy of the spine for correction of flexion deformity in rheumatoid arthritis. Clin Orthop Relat Res 66:6-9, 1969

9. Suk KS, Kim KT, Lee SH, Kim JM: Significance of chin-brow vertical angle in correction of kyphotic deformity of ankylosing spondylitis patients. Spine 28:2001-2005, 2003

10. van Royen BJ, De Gast A: Lumbar osteotomy for correction of thoracolumbar kyphotic deformity in ankylosing spondylitis. A structured review of three methods of treatment. Ann Rheum Dis 58:399-406, 1999

11. van Royen BJ, De Gast A, Smit TH: Deformity planning for sagittal plane corrective osteotomies of the spine in ankylosing spondylitis. Eur Spine J 9:492-498, 2000

12. van Royen BJ, Scheerder FJ, Jansen E, Smit TH: ASKyphoplan: a program for deformity planning in ankylosing spondylitis. Eur Spine J 16: 1445-1449, 2007

13. van Royen BJ, Slot GH: Closing-wedge posterior osteotomy for ankylosing spondylitis. Partial corporectomy and transpedicular fixation in 22 cases. J Bone Joint Surg Br 77:117-121, 1995

14. Yang BP, Ondra SL: A method for calculating the exact angle required during pedicle subtraction osteotomy for fixed sagittal deformity: comparison with the trigonometric method. Neurosurgery 59:ONS458-ONS463, 2006

Manuscript submitted October 12, 2007

Accepted November 6, 2007.

Address correspondence to: B. J. van Royen, M.D., Ph.D., Department of Orthopaedic Surgery, VU University Medical Centre, De Boelelaan, 11171081 HV Amsterdam, The Netherlands. email: bj.vanroyen@vumc.nl. 